\title{
PREDIKSI EROSI PADA LAHAN PETANI AGROFORESTRI DI DAS CILIWUNG HULU, PROVINSI JAWA BARAT
}

\author{
Rini Fitri \\ Dosen Prodi Agroteknologi. Fakultas Pertanian. \\ Universitas Almuslim Bireuen Aceh \\ *E-mail: rinnie_fitrie@yahoo.co.id

\begin{abstract}
ABSTRAK
Erosi tanah pada lahan petani agroforestri di Daerah Aliran Sungai (DAS) Ciliwung Hulu Provinsi Jawa Barat disebabkan oleh penggunaan lahan tanpa teknik konservasi tanah dan air serta pola tanam monokultur. Keberadaan agroforestri di dalam suatu DAS akan membentuk peran stabilitas lereng yang juga memungkinkan penurunan erosi. Penelitian ini dilaksanakan dari bulan April sampai Agustus 2016 di lahan agroforestri petani di DAS Ciliwung Hulu Provinsi Jawa Barat yang secara administrasi termasuk ke wilayah kabupaten Bogor dan Kota Bogor. Adapun tujuan dari penelitian ini adalah untuk memprediksi erosi tanah pada lahan petani agroforestri di DAS Ciliwung Hulu, Provinsi Jawa Barat. Penelitian ini menggunakan metode survei dan prediksi erosi dengan model Universal Soil Loss Equation. Hasil penelitian menunjukkan bahwa prediksi erosi tanah pada penggunaan lahan agroforestri di Sub-DAS Ciliwung Hulu Provinsi Jawa Barat paling rendah berkisar 3.31 ton.ha $^{-1}$ per tahun sedangkan erosi tanah tertinggi terjadi di Sub-DAS Ciesek yaitu 972.31 ton.ha $^{-1}$ per tahun. Erosi tanah ini di prediksi pada tujuh Sub-DAS di DAS Ciliwung Hulu Provinsi Jawa Barat yaitu Sub-DAS Cisuren, Sub-DAS Ciliwung Hulu, Sub-DAS Cisukabirus, Sub-DAS Ciesek, Sub-DAS Cisarua, Sub-DAS Ciseseupan dan Sub-DAS Cibalok.
\end{abstract}

Kata kunci: Agroforestri, DAS, Erosi, Lahan, Jawa Barat

\section{ABSTRACT}

Soil erosion on agroforestry farmland in Ciliwung Hulu Watershed of West Java is caused by land use without soil and water conservation techniques and monoculture planting pattern. The presence of agroforestry within a watershed will form the role of slope stability which also allows for the reduction of erosion. This research was conducted from April to August 2016 in farmer agroforestry field in Ciliwung Hulu Watershed of West Java Province which administratively included to Bogor Regency. The purpose of this research is to predict soil erosion on agroforestry farmer land in Ciliwung Hulu Watershed, West Java Province. This research uses survey method and erosion prediction with Universal Soil Loss Equation model. The results showed that the prediction of soil erosion on agroforestry land use in Ciliwung Hulu Sub-Watersheds of West Java Province was lowest at 3.31 ton.ha-1 per year while the highest soil erosion occurred in the Ciesek Sub-Watersheds at 972.31 ton.hal per year. This soil erosion was predicted on seven Sub-Watersheds in Ciliwung Hulu Watershed of West Java Province ie Cisuren Sub-watersheds, Ciliwung Hulu Sub-Watersheds, Cisukabirus Sub- 
Watersheds, Ciesek Sub- Watersheds, Cisarua Sub- Watersheds, Ciseseupan SubWatersheds and Cibalok Sub-Watersheds.

Keywords: Agroforestry, erosion, land, watershed, West Java

\section{PENDAHULUAN}

Daerah Aliran Sungai (DAS) adalah suatu daerah tertentu yang bentuk dan sifat alamnya sedemikian rupa, sehingga merupakan kesatuan dengan sungai dan anak-anak sungainya yang melalui daerah tersebut dalam fungsinya untuk menampung air yang berasal dari curah hujan dan sumber air lainnya dan kemudian mengalirkannya melalui sungai utamanya (single outlet). Satu DAS dipisahkan dari wilayah lain disekitarnya (DAS lainnya) oleh pemisah dan topografi, seperti punggung perbukitan dan pegunungan.

Pengertian DAS tersebut menggambarkan bahwa DAS merupakan suatu wilayah yang mengalirkan air yang jatuh diatasnya beserta sedimen dan bahan terlarut melalui titik yang sama sepanjang suatu aliran atau sungai. Dengan demikian DAS (watershed) dapat terbagi menjadi beberapa Sub-DAS, sehingga luas DAS pun akan bervariasi dari beberapa puluh meter persegi sampai ratusan ribu hektar tergantung titik pengukuran ditempatkan (Sihite dan Sinukaban, 2004). DAS dapat digolongkan sebagai stok dan komoditas, sebagai stok DAS dapat menghasilkan fungsi-fungsi yang intangible sifatnya sebagai penyimpan air, pencegah banjir dan mempertahankan kesuburan. DAS di Indonesia sebagian besar dalam kondisi kritis seperti dicerminkan sering terjadinya bencana banjir dan kekeringan, pendangkalan waduk dan sungai, serta tanah longsor dan meningkatnya lahan kritis. Keputusan Menteri Kehutanan No. SK.328/Menhut-II/2009 disebutkan bahwa sebesar 108 DAS dalam kondisi kritis yang memerlukan prioritas penangan (Kementerian Kehutanan, 2013).

Penurunan kualitas lahan dan hutan diberbagai daerah aliran sungai (DAS) di Indonesia saat ini diindikasikan oleh perluasan lahan kritis. Luas lahan kritis di Indonesia sampai 2007 sudah mencapai 30.196.799,92 ha, yang terdiri atas 10.690.312 ha di luar kawasan hutan dan 19.506.487,92 ha di dalam kawasan hutan (Ditjen RLPS 2007). Peningkatan luas lahan kritis ini diakibatkan oleh banyaknya konversi lahan hutan menjadi lahan non hutan. Hal ini berkontribusi terhadap kerusakan DAS di Indonesia, sehingga sampai tahun 2004 sudah terdapat 65 DAS tergolong kedalam kritis prioritas I (Ditjen Sumberdaya Air, 2004). Daya dukung DAS sebagai penyangga kehidupan saat ini mangalami perubahan fungsi lahan dan hutan mengalami degradasi di berbagai wilayah di Indonesia. Luas hutan mengalami pengurangan dalam DAS berdampak terhadap meningkatnya erosi, aliran permukaan dan debit puncak (Alwi et al., 2014; Nurrizqi dan Suyono 2014). Berdasarkan permasalahan yang dikemukakan di atas, pentingnya memprediksi erosi tanah yang terjadi pada lahan agroforestri petani di DAS Ciliwung Hulu untuk mewujudkan pengelolaan DAS berkelanjutan. Adapun tujuan dari penelitian ini adalah untuk memprediksi erosi tanah pada lahan petani agroforestri di DAS Ciliwung Hulu Provinsi Jawa Barat.

\section{METODE}

\section{Alat dan Bahan}

Peralatan yang digunakan dalam penelitian ini adalah Global Positioning 
System (GPS), peta kerja, abney level, meteran, pisau, bor tanah, kompas, ring sample, kantong plastik, kamera digital, alat tulis, seperangkat komputer dan hard disk external untuk menyimpan data. Bahan-bahan yang digunakan dalam penelitian ini adalah bahan kimia yang digunakan untuk analisis sampel tanah di laboratorium.

\section{Teknik Pengumpulan Data, Tahapan Penelitian dan Analisis Data}

Jenis-jenis data yang dibutuhkan dalam penelitian ini terdiri dari data primer dan data sekunder. Data primer didapat langsung dari observasi lapangan dan analisis sampel tanah di laboratorium. Data sekunder diperoleh berdasarkan studi referensi dari berbagai sumber seperti institusi pemerintah daerah setempat serta terkait hasil-hasil penelitian. Matrik, tujuan penelitian, data yang dibutuhkan, teknik pengumpulan data, teknik analisis data dan output yang diharapkan disajikan pada Tabel 1.

Tabel 1. Data yang dibutuhkan, teknik pengumpulan data, teknik analisis data dan output yang diharapkan disajikan pada Tabel 1.

\begin{tabular}{|c|c|c|c|c|c|}
\hline No & Tujuan & Jenis data & $\begin{array}{c}\text { Teknik } \\
\text { pengumpulan } \\
\text { data }\end{array}$ & $\begin{array}{c}\text { Teknik analisis } \\
\text { data }\end{array}$ & $\begin{array}{c}\text { Output } \\
\text { yang } \\
\text { diharapkan }\end{array}$ \\
\hline \multirow[t]{3}{*}{ I } & \multirow{3}{*}{$\begin{array}{l}\text { Aspek Biofisik } \\
\text { (Penggunaan } \\
\text { Lahan 1:50.000 } \\
\text { Satuan Unit } \\
\text { Lahan) }\end{array}$} & $\begin{array}{l}\text { 1. Peta jenis } \\
\text { tanah }\end{array}$ & \multirow{2}{*}{$\begin{array}{l}\text { Data Balai } \\
\text { Penelitian } \\
\text { Tanah. }\end{array}$} & \multirow[b]{3}{*}{ Overlay } & \multirow{3}{*}{$\begin{array}{c}\text { Peta satuan } \\
\text { unit lahan } \\
\text { digunakan } \\
\text { dalam } \\
\text { pendugaan } \\
\text { erosi. }\end{array}$} \\
\hline & & $\begin{array}{ll}\text { 2. } & \text { Peta } \\
\text { topografi }\end{array}$ & & & \\
\hline & & $\begin{array}{l}\text { 3. Peta } \\
\text { Penggunaan } \\
\text { lahan }\end{array}$ & $\begin{array}{l}\text { Hasil } \\
\text { interpretasi } \\
\text { citra spot_6 } \\
\text { dan peta Rupa } \\
\text { Bumi } \\
\text { Indonesia }\end{array}$ & & \\
\hline \multirow[t]{9}{*}{ II } & $\begin{array}{l}\text { Aspek Biofisik } \\
\text { (Prediksi Erosi) }\end{array}$ & & & \multirow{9}{*}{$\begin{array}{l}R=\sum_{t=1}^{t=12} E I 30 \\
6.119 \times(\mathrm{CH})^{1.21} \\
\mathrm{x}(\mathrm{HH})^{0.47} \mathrm{x} \\
\mathrm{CHmax}{ }^{0.53} \\
\mathrm{~K}=\text { Wischmeier } \\
\& \text { Smith } 1978 ; \mathrm{LS} \\
=\text { Dephut, 2001; } \\
\text { C\& P = Pedoman } \\
\text { (Arsyad, 2000) } \\
\text { Etol = Pedoman } \\
\text { nilai T tanah- } \\
\text { tanah di Indonesia } \\
\text { (Arsyad, 2000) }\end{array}$} & \multirow{9}{*}{$\begin{array}{l}\text { Erosi } \\
\text { aktual }\end{array}$} \\
\hline & \multirow{5}{*}{ 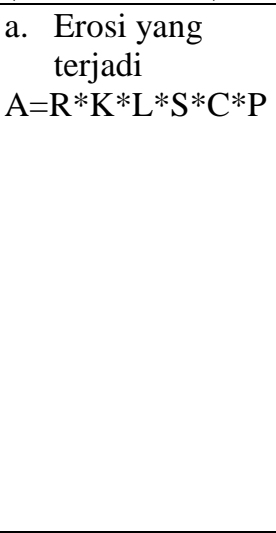 } & $\begin{array}{l}\text { 1. Erosivitas } \\
(\mathrm{R})\end{array}$ & $\begin{array}{l}\mathrm{CH} \text { dari } \\
\text { penekar hujan }\end{array}$ & & \\
\hline & & $\begin{array}{l}\text { 2. Erodibilitas } \\
(\mathrm{K})\end{array}$ & $\begin{array}{l}\text { Tekstur \& BO } \\
\text { dari hasil } \\
\text { analisis lab, } \\
\text { struktur \& } \\
\text { permeabilitas } \\
\text { tanah diamati } \\
\text { di lapangan }\end{array}$ & & \\
\hline & & $\begin{array}{l}\text { 3. Kelerengan } \\
\text { (LS) }\end{array}$ & \multirow{3}{*}{$\begin{array}{l}\text { Pengamatan di } \\
\text { lapang }\end{array}$} & & \\
\hline & & 4. Faktor $\mathrm{C}$ & & & \\
\hline & & 5. Faktor P & & & \\
\hline & \multirow{3}{*}{$\begin{array}{l}\text { b. Pendugaan } \\
\text { Etol }\end{array}$} & 1. Tekstur & \multirow[b]{2}{*}{$\begin{array}{l}\text { Analisis lab } \\
\text { dan amati di } \\
\text { lapangan }\end{array}$} & & \\
\hline & & $\begin{array}{ll}\text { 2. } & \text { Berat } \\
\text { volume } \\
\text {.tanah }\end{array}$ & & & \\
\hline & & $\begin{array}{l}\text { 3. Kedalaman } \\
\text { tanah }\end{array}$ & $\begin{array}{l}\text { Pengamatan } \\
\text { lapang dan } \\
\text { pustaka }\end{array}$ & & \\
\hline
\end{tabular}




\section{Penentuan Satuan Unit Lahan}

Satuan unit lahan yang dijadikan pengamatan intensif dilokasi penelitian adalah satuan unit lahan yang terdapat di DAS Ciliwung Hulu. Penentuan satuan unit lahan berdsarkan tumpang tindih (overlay) peta jenis tanah $1: 50.000$, peta penggunaan lahan 1 : 50.000 dan peta lereng $1: 50.000$. Satuan unit lahan yang didapat dari hasil overlay peta ini dijadikan untuk pengamatan dilapangan dan unit analisis dan prediksi erosi.

\section{Prediksi Erosi}

Prediksi erosi pada sebidang tanah adalah metode untuk memperkirakan laju erosi yang akan terjadi dari tanah yang digunakan dalam suatu penggunaan lahan. Pendugaan erosi dilakukan pada setiap satuan lahan dan tipe usahatani dengan menggunakan persamaan Universal Soil Loss Equation (USLE) (Wischmeier dan Smith 1978). Data ini digunakan untuk merencanakan tipe usahatani agroforestry berbasis hortikultura dan agroteknologi yang sesuai pada setiap satuan lahan di DAS Ciliwung Hulu. Persamaan USLE yang digunakan untuk prediksi erosi adalah sebagai berikut:

$$
\mathbf{A}=\mathbf{R} * \mathbf{K} * \mathbf{L} * \mathbf{S} * \mathbf{C} * \mathbf{P}
$$

Keterangan:
$\mathrm{A}=$ banyaknya tanah yang tererosi (ton.ha ${ }^{-1}$ per tahun)
$\mathrm{R}=$ faktor indeks (erosivitas) hujan
$\mathrm{K}=$ faktor erodibilitas tanah
$\mathrm{L}=$ faktor panjang lereng
$\mathrm{S}=$ faktor kecuraman lereng
$\mathrm{C}=$ faktor vegetasi penutup tanah dan pengelolaan tanaman
$\begin{aligned} \mathrm{P}= & \text { faktor tindakan-tindakan khusus } \\ & \text { konservasi tanah }\end{aligned}$

\section{HASIL DAN PEMBAHASAN}

\section{Erosi pada Tipe Agroforestri di DAS Ciliwung Hulu}

Prediksi erosi dilakukan pada penggunaan lahan agroforestri di tujuh Sub-DAS yang ada di DAS Ciliwung Hulu, yaitu Sub-DAS Cisuren, Sub-DAS Ciliwung Hulu, Sub-DAS Cisukabirus, Sub-DAS Ciesek, Sub-DAS Ciseseupan, Sub-DAS Cibalok, dan Sub-DAS Cisarua. Prediksi erosi pada lahan agroforestri di DAS Ciliwung Hulu paling rendah pada Sub-DAS Ciliwung Hulu berkisar 3.31 ton.ha $^{-1}$ per tahun sedangkan erosi tertinggi terjadi di Sub-DAS Ciesek yaitu sebesar 972.31 ton.ha $^{-1}$ per tahun. Erosi yang paling tinggi terjadi pada Sub-DAS Ciesek dengan kemiringan lerengnya $15 \%$ - 25\% dan Sub-DAS Ciliwung Hulu dengan kemiringan lerengnya dibawah 8\%. Hasil perhitungan prediksi erosi pada penggunaan lahan agroforestri disajikan pada Tabel 2.

Tingginya erosi yang terjadi pada tipe agrosilvopastura-d di Sub-DAS Ciesek, disebabkan oleh tingkat penutupan vegetasi yang relatif rendah. Vegetasi rumput di permukaan tanah hanya $20 \%$. Hal ini karena petani secara rutin melakukan penyiangan sehingga penutup lahan pada tipe agrosilvopastura-d ini tidak optimal. Sesuai dengan Sinukaban (1999) yang mengatakan bahwa penutupan tanah oleh tajuk tanaman dapat membantu mengimbangi pengaruh curah hujan terhadap erosi dan aliran permukaan. Berdasarkan rumus perhitungan nilai erodibilitas tanah $(\mathrm{K})$ pada lahan agroforestri di DAS Ciliwung Hulu, diperoleh nilai erodibilitas tanah pada daerah penelitian berkisar dari 0,02 (sangat rendah) sampai 0,24 (sedang). Erodibilitas tanah dipengaruhi oleh sifat- 
sifat tanah yang mempengaruhi laju infiltrasi, permeabilitas, dan kapasitas tanah menahan air dan sifat-sifat tanah yang mempengaruhi ketahanan struktur tanah terhadap dispersi, pengikisan oleh butir-butir air hujan dan aliran permukaan. Erodibilitas tanah sangat penting untuk diketahui agar tindakan konservasi dan pengelolaan tanah pada sistem agroforestri dapat dilaksanakan secara lebih tepat dan terarah.

Tabel 2. Erosi actual dan erosi yang dapat ditoleransikan pada unit lahan agroforestri di DAS Ciliwung Hulu

\begin{tabular}{|c|c|c|c|c|}
\hline \multirow[t]{2}{*}{ Sub DAS } & \multirow[t]{2}{*}{$\begin{array}{l}\text { Kemiringan } \\
\text { Lereng }\end{array}$} & \multirow[t]{2}{*}{ Tipe agroforestri } & Erosi aktual & $\begin{array}{c}\text { Erosi yang } \\
\text { dapat } \\
\text { ditoleransikan }\end{array}$ \\
\hline & & & \multicolumn{2}{|c|}{--- ton.ha $^{-1}$ per tahun --- } \\
\hline \multirow{3}{*}{ Cisuren } & $25 \%-40 \%$ & Agrosilvopastura-d & 226.40 & 12.36 \\
\hline & $8 \%-15 \%$ & Agrisilvikultur-d & 37.35 & 19.25 \\
\hline & $8 \%-15 \%$ & Agrisilvikultur-j & 38.08 & 16.80 \\
\hline \multirow[t]{3}{*}{ Ciliwung Hulu } & $<8 \%$ & Agrosilvopastura-m & 3.31 & 21.93 \\
\hline & $15 \%-25 \%$ & Agrisilvikultur- $a$ & 247.58 & 17.55 \\
\hline & $15 \%-25 \%$ & Agrisilvikultur- $a$ & 135.04 & 12.26 \\
\hline \multirow[t]{3}{*}{ Cisukabirus } & $8 \%-15 \%$ & Agrosilvopastura-d & 9.53 & 15.40 \\
\hline & $15 \%-25 \%$ & Agrisilvikultur-j & 66.26 & 17.71 \\
\hline & $8 \%-15 \%$ & Agrisilvikultur- $j$ & 7.66 & 12.48 \\
\hline \multirow[t]{3}{*}{ Ciesek } & $15 \%-25 \%$ & Agrosilvopastura-d & 972.31 & 12.00 \\
\hline & $8 \%-15 \%$ & Agrisilvikultur- $a$ & 38.13 & 14.70 \\
\hline & $15 \%-25 \%$ & Agrosilvopastura-s & 292.59 & 11.89 \\
\hline \multirow[t]{3}{*}{ Cisesepan } & $8 \%-15 \%$ & Agrosilvopastura-a & 19.06 & 15.93 \\
\hline & $8 \%-15 \%$ & Agrisilvikultur- $a$ & 49.45 & 15.04 \\
\hline & $8 \%-15 \%$ & Agrosilvopastura- $a$ & 33.85 & 22.75 \\
\hline \multirow[t]{2}{*}{ Cibalok } & $8 \%-15 \%$ & Agrisilvikultur- $a$ & 59.55 & 12.87 \\
\hline & $8 \%-15 \%$ & Agrisilvikultur- $a$ & 24.10 & 9.45 \\
\hline \multirow[t]{2}{*}{ Cisarua } & $8 \%-15 \%$ & Agrosilvopastura-a & 144.91 & 34.65 \\
\hline & $15 \%-25 \%$ & Agrisilvikultur-a & 46.38 & 66.89 \\
\hline
\end{tabular}

\section{Erosi yang Dapat Ditoleransikan}

Hasil penelitian menunjukkan bahwa nilai erosi yang dapat ditoleransikan (Etol) yang terjadi di DAS Ciliwung Hulu paling rendah pada Sub-DAS Cibalok berkisar 9.45 ton.ha ${ }^{-1}$ per tahun sedangkan erosi yang ditoleransikan tertinggi sebesar 66.89 ton.ha $^{-1}$ per tahun di Sub-DAS Cisarua. Erosi dan erosi yang dapat ditoleransikan serta tingkat bahaya erosi disajikan pada Tabel 2.

Erosi mengakibatkan hilangnya lapisan tanah bagian atas yang mengadung bahan organik sehingga berkurangnya kemampuan tanah untuk penyerapan air kedalam tanah dan kemampuan menahan air. Oleh sebab itu, indikasi awal penyebab terjadinya degradasi lahan dapat terlihat apabila besarnya erosi yang terjadi lebih besar dari erosi yang ditoleransikan. Menurut Arsyad (2000) tanah yang berkadar liat tinggi memiliki berat volume tanah berkisar dari 1 hingga 1,2. Nilai erosi yang dapat ditoleransikan adalah sebesar 20 ton.ha ${ }^{-1}$ per tahun.

\section{SIMPULAN}

Prediksi erosi tanah pada penggunaan lahan agroforestri di Sub-DAS Ciliwung 
Hulu Provinsi Jawa Barat paling rendah berkisar 3.31 ton. $\mathrm{h}^{-1}$ per tahun, sedangkan erosi tanah tertinggi terjadi di Sub-DAS Ciesek yaitu 972.31 ton. $^{-1}$ per tahun. Erosi tanah ini di prediksi pada tujuh SubDAS di DAS Ciliwung Hulu Provinsi Jawa Barat yaitu Sub-DAS Cisuren, SubDAS Ciliwung Hulu, Sub-DAS Cisukabirus, Sub-DAS DAS Ciesek, SubDAS Cisarua, Sub-DAS Ciseseupan dan Sub-DAS Cibalok.

\section{DAFTAR PUSTAKA}

Alwi, L.O., N. Sinukaban, S. Solahuddin, dan H. Pawitan. 2014. Kajian Dampak Dinamika Penggunaan Lahan Terhadap Erosi dan Kondisi Hidrologi DAS Wanggu DS (Study Of Land Use Dynamic Impacts To Land Erosion And Hydrology Conditions In Wanggu Watershed). J Hidrolitan, Vol. 2 (2): $74-86$.

Arsyad, S. 2000. Konservasi tanah dan air. IPB Pr. Bogor.

[Ditjen RLPS] Direktorat Jenderal Rehabilitasi Lahan Perhutanan Sosial. 2007. Data Lahan Kritis Nasional. Departemen Kehutanan. Jakarta.

[Ditjen Sumberdaya Air] Direktorat Jenderal Sumberdaya Air Departemen Pertanian 2004. Sebanyak 65 DAS dalam kondisi semakin kritis. Harian
Kompas, 20 Agustus 2004. Hal 15. Jakarta.

Kementerian Kehutanan. 2013. Peraturan Menteri tentang Tata Cara Penyusunan dan Penetapan Rencana Pengelolaan DAS. Jakarta

Nurrizqi dan Suyono. 2012. Pengaruh Perubahan Penggunaan Lahan Terhadap Perubahan Debit Puncak Banjir Di Sub-DAS Brantas Hulu. J Bumi Indonesia, Vol. 1 (3): 365 - 369.

Sihite, J dan N. Sinukaban. 2004. Economic Valuation of Land Use Changes in Besai Sub Watershed Tulang Bawang, Lampung. Proceedings of International Seminar on Towards Harmonization Between Development and Environmental Conservation in Biological Productin. 3 - 5 Desember 2004. Cilegon, Indonesia. [En.]

Sinukaban N. 1999. Masalah dan konsepsi pengembangan daerah aliran sungai. Makalah pada seminar sehari tentang pengelolaan DAS terpadu di Sulawesi Tenggara. Universitas Haluoleo, Kendari, Sulawesi Tenggara, 1 Nopember 1999.

Sinukaban, N. 2007. Pengelolaan DAS. Materi Kuliah Pengelolaan DAS. Sekolah Pascasarjana IPB. Bogor. 